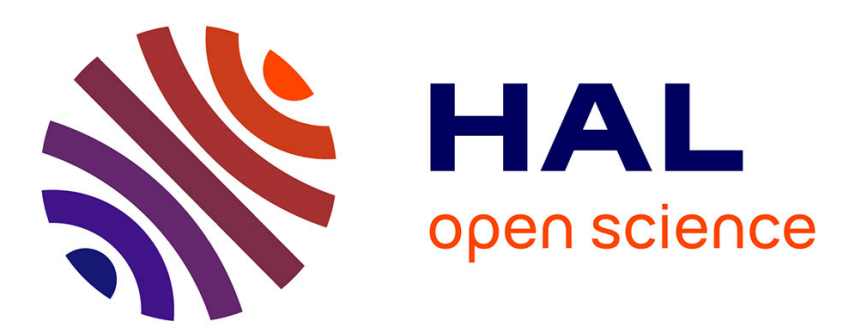

\title{
Modelling crack propagation and arrest in gas pipes using CTOA criterion
}

M Benamara, G Pluvinage, Julien Capelle, Z Azari

\section{To cite this version:}

M Benamara, G Pluvinage, Julien Capelle, Z Azari. Modelling crack propagation and arrest in gas pipes using CTOA criterion. Lecture Notes in Mechanical Engineering, 2017, Fracture at all Scales, pp.171-194. 10.1007/978-3-319-32634-4_9 . hal-02972687

\section{HAL Id: hal-02972687 \\ https://hal.science/hal-02972687}

Submitted on 20 Oct 2020

HAL is a multi-disciplinary open access archive for the deposit and dissemination of scientific research documents, whether they are published or not. The documents may come from teaching and research institutions in France or abroad, or from public or private research centers.
L'archive ouverte pluridisciplinaire HAL, est destinée au dépôt et à la diffusion de documents scientifiques de niveau recherche, publiés ou non, émanant des établissements d'enseignement et de recherche français ou étrangers, des laboratoires publics ou privés. 


\title{
MODELLING CRACK PROPAGATION
}

\section{AND ARREST IN GAS PIPES USING CTOA CRITERION}

\author{
M.Benamara ${ }^{1}$, G.Pluvinage ${ }^{2}$, J.Capelle ${ }^{1}$, Z.Azari ${ }^{1}$ \\ ${ }^{1}$ LaBPS - ENIM, 1 route d'Ars Laquenexy, CS 65820, 57078 Metz, France \\ ${ }^{2}$ FM.C 57530 Silly Sur-Nied, France
}

\begin{abstract}
In this paper, the resistance to ductile crack extension is discussed in terms of Charpy or DWTT energy, R curve and CTOA. Methods used in numerical simulations of ductile crack extension are presented including the cohesive zone model, a critical damage with the Gurson-Tvergaard-Needleman model, critical damage given by SRDD model or a critical crack opening angle (CTOA). Selection of CTOA is based on the reduced number of parameters and the low sensitivity to pipe geometry. Numerical simulations of crack propagation and arrest based on CTOA, use the node release technique, which is described. Results on a pipe made in steel API L X65 are presented. The influence of geometrical and material parameters on crack arrest and velocity using this technique are presented. Finally, an arrest pressure equation similar to the BTCM's equation but including critical CTOA is introduced. For the same decompression wave pressure, the crack propagation velocity is inversely proportional to the resistance to crack extension of the material, which is the dominant parameter. The crack velocity versus decompression is expressed by a $\mathrm{CTOA}_{c}$ function of resistance to crack extension
\end{abstract}

\section{INTRODUCTION}

In several spectacular brittle fractures in 1950s and 1960s in gas pipelines, crack running for several kilometres until arrest occurred at a valve site or upon reaching a heavier wall pipe. These long crack propagations are explained by the fact that crack velocity in a pipe made in a brittle material is faster than the decompression wave velocity of the gas. Therefore the crack tip is always submitted to the service hoop stress. Research on prevention of such a kind of fracture in gas pipelines is, at this time, focused on the brittle-ductile transition behaviour of pipe steel. Eiber [1] found that the Charpy test tends to give an assessment about unsafe situations. In the late 1960s, progress in steel pipe manufacturing led to pipelines also failing by ductile fracture. For these steels, the crack velocity is much slower than for brittle fracture. A significant plasticity near the crack tip, bulging and opening of the pipe reduces crack velocity. The ductile character can be easily seen of the fracture surface where the typical cups and cones fractographic aspect is easily recognisable. Therefore the gas decompression wave could interact with the crack tip. After fracture initiation, the pipe is fully open and there will always be some length of pipe ruptured before the decompression that causes the hoop stress to fall below the arrest level.

This occurs on a distance considerably less than for brittle fracture. One of the objectives of the pipe design is to reduce the crack arrest length in order to repair within a reasonable cost. To solve this problem, developing relationships are required between the decompression behaviour, arrest stress level, and fracture velocity.

The basic idea is to compare fracture resistance and driving force during crack extension. Immediately, when a trough crack appears at the surface of the wall of the pipeline, the gas tends to escape through the opening plug created. This leads to a sudden decompression and creation of two opposite decompression waves running at a speed of the order of $300 \mathrm{~m} / \mathrm{s}$ along the main direction of the pipe. These waves play the major role on the dynamics of pipe fracture. If the decompression wave celerity is less than the crack propagation speed, the crack tip is constantly loaded at initial pressure, inducing stationary crack propagation. On the contrary, the crack is progressively less unloaded until arrest. 


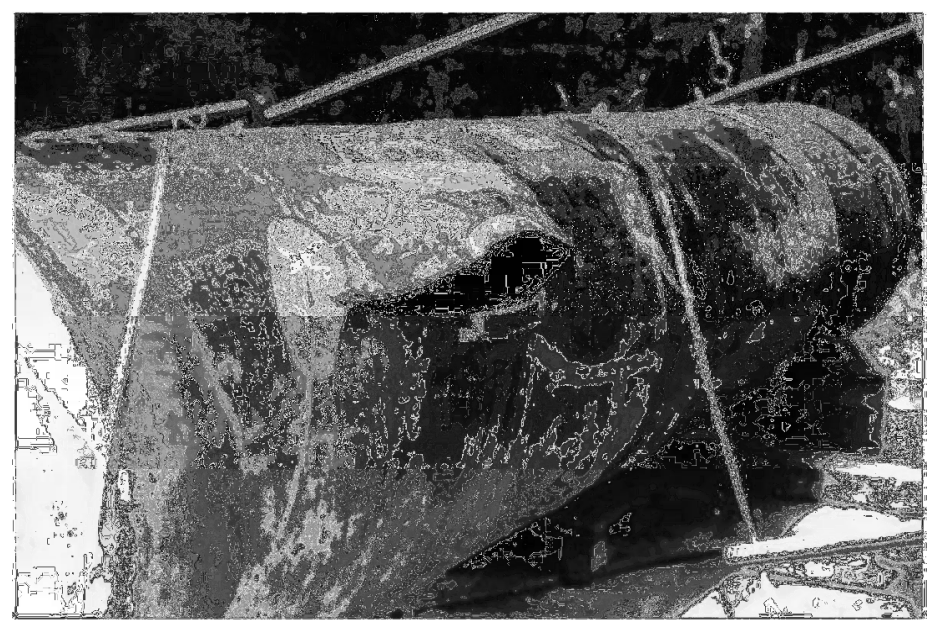

Fig. 1: Burst test of a pipe made in X52 pipe steel.

This approach is the basis of the Two-Curves Method (TCM), which involves the comparison of two curves: the gas decompression pressure versus its velocity and the fracture resistance versus crack velocity. Several twocurve models have been introduced successively: the Batelle Two Curves method BTCM [2], the High Strength Line Pipe (HLP) [3] and the HLP-Sumitomo [4] methods. In practice, the TCM approach consists of comparing the curves of the driving and resistance forces. The relative positions of the two curves determine the potential for sustained fracture propagation or its arrest. If the two curves intersect, the fracture velocity is equal to the decompression wave speed and crack propagation will continue indefinitely at a constant speed. Nonintersection means that the decompression wave overruns the fracture propagation for all pressure levels and crack arrest occurs. All TCM models are based on the assumption that the decompression wave speed is uncoupled from the fracture velocity.

Decompression pressure wave velocity is obtained by numerical models such as the Finite Difference Method (FDM) and the Method of Characteristics (MOC), or experimental methods as shock tubes. Generally one assumes a one-dimensional flux along the pipe axis and isentropic behaviour. In BTCM, HLP and HLP Sumitomo, the decompression pressure wave velocity is modelled by adopting these assumptions and using the equation of state of Benedict-Webb-Rubin-Starling (BWRS) with adjustable constants to estimate the thermodynamic parameters during the isentropic decompression. The relative pressure at crack tip is given by;

$$
\frac{p_{d}}{p_{0}}=\left(\frac{V_{d}}{6 V_{a}}+0.83\right)^{7}
$$

where $\mathrm{p}_{0}$ is the initial pressure, $\mathrm{p}_{\mathrm{d}}$ the decompression wave pressure, $\mathrm{V}_{\mathrm{d}}$ the decompression wave celerity and $\mathrm{V}_{\mathrm{a}}$ the gas acoustic celerity.

The major difference between the 3 TCM leads to the definition of the resistance to crack extension. In the initial BTCM model, the fracture resistance to crack extension $R_{f}$ is given by the Charpy Energy $C_{V}$. The BTCM is limited to low pressure pipes made in steel with low yield stress. In order to overcome these limitations, HLP has proposed to use as fracture resistance to crack extension the drop weight test tearing energy (DWTT). Later HLP-Sumitomo proposed for high strength steel to correct DWTT energy by pipe diameter and thickness. In this paper, we propose to extend the two curves method concept by using crack tip opening angle (CTOA) as a measure of fracture resistance and using a simplified gas depressurisation model, where gas pressure is a function of time and distance from the crack tip. We first discuss the different approach to define the fracture resistance to crack extension and justify the choice of CTOA by the fact that this parameter is directly connected with crack extension and does not take into account fracture resistance to crack initiation.

We discuss also the different method to modelling numerically crack extension; R-curve, cohesive zone model (CZM), Gurson-Tvergaard-Needleman model (GTN), the strain rate dependent damage model (SRDD) and 
CTOA model. We justify our choice of the CTOA model by the reducing the number of parameters, leading to less dependency on pipe geometry and reduced computing time. Examples of prediction of arrest pressure and length are given in the case of a pipe of $355 \mathrm{~mm}$ diameter and $19 \mathrm{~mm}$ wall thickness, made in pipe steel API5L X 65 .

The influence of geometrical and material parameters on crack arrest and crack velocity is finally discussed.

\section{THE RESISTANCE TO CRACK EXTENSION}

As a crack grows, the driving force for further crack growth will change. A plot of the crack driving force expressed in terms of stress intensity factor (SIF), $\mathrm{J}$ integral (J) or crack-tip opening displacement (CTOD) against crack extension is known as an R-curve. R-curves may be used to analyse the potential for crack-growth initiation and extension. Generally, materials display either a flat $\mathrm{R}$ curve or a rising $\mathrm{R}$ curve. For a flat $\mathrm{R}$ curve, material resistance is constant with respect to crack extension. Nonlinear behaviour, like ductile fracture, can result in a rising $\mathrm{R}$ curve as the plastic zone at crack tip increases in size with extension.

Conditions of stable crack growth require that the rate of change of the crack driving force with increasing crack length $\Delta \mathrm{a}$ be smaller than the increase of crack growth resistance expressed in terms of crack opening displacement $\delta$ :

$$
\frac{d \delta}{d a} \leq \frac{d \delta_{R}}{d a}
$$

One example of a J-R curve obtained on a pipe steel SA333 Gr6 with a yield stress, $\sigma_{\mathrm{y}}=288 \mathrm{MPa}$ and ultimate tensile stress $\sigma_{\mathrm{u}} 420 \mathrm{MPa}$ is given in Fig. 2 [5]. Test specimens consist of straight pipes with a throughwall circumferential crack in the middle of its length.

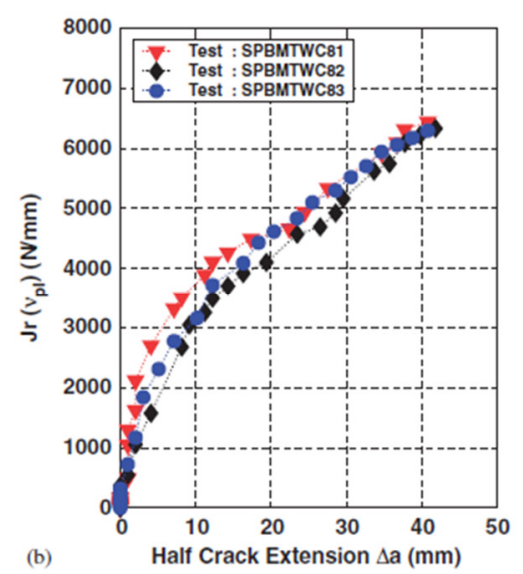

Fig. 2: J-R curve obtained on a pipe steel SA333 Gr6 [5].

In standard methods for determining crack extension in pipes such as the BTCM [2], HLP [3], and HLPSumitomo [4], fracture resistance to crack extension $R_{f}$ is described as the specific fracture energy i.e. energy per fracture surface. $R_{f}$ obtained either from the Charpy-V energy $C_{v}\left(R_{f}=C_{v} / A\right)$ or either from DWTT energy $\mathrm{U}_{\text {DWTT }}\left(\mathrm{R}_{\mathrm{f}}=\mathrm{U}_{\text {DWTT }} / A\right)$ from standard or embrittled specimens. $A$ is the fracture surface.

The specific fracture energy obtained from Charpy specimens consists of two parts: energy for crack initiation and energy for crack extension. The ratio of energy for crack extension to total energy decreases when the yield stress of the material decreases. Examination of an instrumented Charpy test on X65 pipe steel indicates the difficulty of using Charpy energy as fracture resistance to ductile crack extension.For API $5 \mathrm{LX} 65$ at $20{ }^{\circ} \mathrm{C}$, the ratio of energy for fracture initiation $\mathrm{U}_{\mathrm{i}}$ to energy for fracture $\mathrm{C}_{\mathrm{v}}$ is $21.3 \%$. A comparison with the $\mathrm{X} 52$ pipe steel is made in Table 1, and indicates that this ratio decreases when the yield stress increases.

In the HLP method [3], the pre-crack DWTT absorbed energy has been proposed as a better indicator to express resistance to fracture propagation, as a similar fracture surface to the running ductile fracture. For API 5LX65 at $20{ }^{\circ} \mathrm{C}$, the ratio of energy for fracture initiation to energy for fracture is $32.4 \%$. The value of this ratio is higher 
than that obtained from the Charpy test and does not follow the argument in favour of DWTT energy used as fracture resistance for a running crack.

Table 1: Ratio of energy for fracture initiation

to total energy for fracture for X52 and X65 pipe steel in the Charpy test.

\begin{tabular}{|l|l|l|}
\hline & Yield stress & $\mathrm{U}_{\mathrm{i}} / \mathrm{C}_{\mathrm{v}}$ \\
\hline $\mathrm{X} 65$ & 465 & $21.3 \%$ \\
\hline $\mathrm{X} 52$ & 436 & $26.54 \%$ \\
\hline
\end{tabular}

To overcome the difficulty in using a fracture resistance parameter including the energy for fracture initiation, Demofonti et al. [6] proposed a method of subtracting energy for fracture initiation $U_{i}$ by finding the difference between the fracture energies of two similar DWTT specimens, but with different initial notch depths of $a_{1}=10$ $\mathrm{mm}$ and $\mathrm{a}_{2}=38 \mathrm{~mm}$ respectively.

Here the concept of Crack Tip Opening Angle (CTOA) [7] is used to simulate stable crack growth by the finite element method. The CTOA $\Psi$ is defined as the angle between the crack faces of a growing crack. Crack-growth dependence of this angle was expected, and a constant value was used for all of the stages of growth. The value at the first increment of crack growth is called $\psi_{0}$ (Fig. 3) and $\psi_{\mathrm{c}}$ is called critical crack tip opening angle $\left(\mathrm{CTOA}_{\mathrm{c}}\right)$ with. $\psi_{\mathrm{c}}<\psi_{0}$.

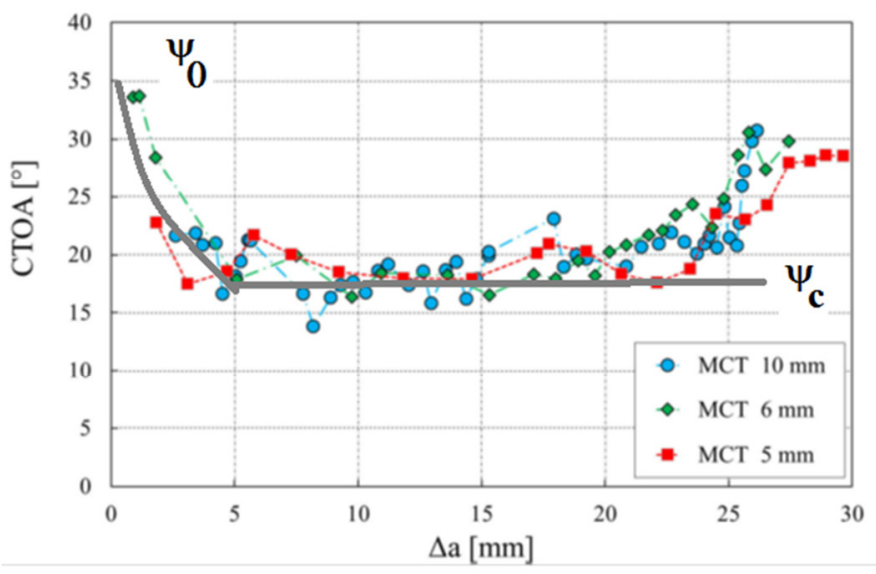

Fig. 3: Evolution of CTOA during crack extension.

Since the 1990s, the use of this criterion has been extended to numerical simulations by the finite element method (FEM) of the crack extension.

Nowadays, $\mathrm{CTOA}_{\mathrm{c}}$ is used to predict crack length and pressure at arrest of a ductile running crack and particularly in gas pipes [8]. A correlation between Charpy-V energy $\mathrm{K}_{\mathrm{CV}}$ and CTOA has been proposed in [9], where CTOA is in degrees and $\mathrm{K}_{\mathrm{CV}}$ in Joules.

$$
\Psi_{c}=0.05 K_{C V}
$$

Fracture resistance to crack extension $\mathrm{R}_{\mathrm{f}}$ refers strictly to crack propagation. Therefore the use of the fracture test including energy for fracture initiation is doubtful. This is the case for $\mathrm{R}_{\mathrm{f}}$ defined from Charpy or DWTT energies; however, they are popular and are used in standards for pipe design. A parameter defined from the $\mathrm{R}$ curve like CTOA is therefore preferable.

\section{NUMERICAL SIMULATION OF CRACK EXTENSION IN PIPES}

Modelling ductile crack propagation by numerical methods generally uses the node release technique. This technique allows a crack extension over a length equal to the mesh size. Crack extension occurs when energetic, 
damage or geometric conditions occurs at crack tip. The criteria generally used for that are: a dissipative energy with the cohesive zone model (CZM) [10], a critical damage with the Gurson-Tvergaard-Needleman model (GTN)[10], critical damage given by SRDD model [11] or a critical crack opening angle $\left(\mathrm{CTOA}_{c}\right)$ [8]. Results are generally sensitive to mesh size.

\subsection{Cohesive zone model}

Using the CZM model, fracture extension is regarded as a gradual phenomenon in which the separation of the crack takes place across an extended crack tip or cohesive zone. The fracture resistance is simulated by cohesive tractions. As the surfaces separate, the opening stress first increases until a maximum $\sigma_{\max }$ is reached and then subsequently decreases to zero, which results in complete separation. The variation in traction in relation to displacement is plotted on a curve called the traction-displacement curve. The area under this curve is equal to the energy needed for separation $\square_{c}$.

The specific work of fracture $\mathrm{w}_{\mathrm{f}}$, according to Cotterell et al. [12], can then be deduced.

$$
w_{f}=\frac{d \Gamma_{c}}{B d a}=\int_{0}^{\Delta}\left(\sigma_{\max } \frac{d \delta}{d a}\right) d x
$$

where $B$ is the plate thickness, $\sigma_{\max }$ the cohesive stress, $\delta$ is the crack opening displacement. The cohesive distance $\Delta$ is chosen as a characteristic distance independent of the mesh element size and can be obtained by a calibration procedure.

For an API 5L X 65 steel pipe, Scheider et al. [10] proposed the values of $\sigma_{\max }$ and $\Gamma_{\mathrm{c}}$ given in Table 2.

Table 2: Values of the parameters $\sigma_{\max }$ and $\Gamma_{0}$ of the cohesive zone model for API 5L X 65.

\begin{tabular}{|l|l|l|}
\hline CZM parameters & $\square_{\max }(\mathrm{MPa})$ & $\square_{\mathrm{c}}(\mathrm{N} / \mathrm{mm})$ \\
\hline API 5L X 65 & 1375 & 900 \\
\hline
\end{tabular}

Simulations of ductile cracking with the CZM are generally performed using a coarser mesh, and this reduces the number of elements. The model is sensitive to the shape of the traction-displacement curve. This is a strong limitation of the validity of the method.

\subsection{Gurson-Tvergaard-Needleman model}

The Gurson-Tvergaard-Needleman (GTN) model consists of 4 elements: the GTN yield locus , the plastic flow rule, the hardening equation and the damage evolution law. The GTN damage model considers that the yield locus $\Phi$ is affected by porosities that are created during the ductile fracture process. It is a function of hydrostatic pressure $\sigma_{\mathrm{h}}$ and the effective porosity $\mathrm{f}^{*}$.

$$
\Phi=\left(\frac{\sigma_{e q}}{R_{c}}\right)+2 q_{1} f^{*} * \cosh \left[-q_{2} \cdot\left(\frac{3 \sigma_{h}}{2 R_{c}}\right)\right]-\left(1+q_{3} f^{* 2}\right)
$$

$\mathrm{q}_{1}, \mathrm{q}_{2}$ and $\mathrm{q}_{3}$ are the parameters of the GTN model. The plastic flow rule obeys the normality principle:

$$
\begin{gathered}
\epsilon_{p}=\eta \frac{\partial \Phi}{\partial \sigma} \\
\eta\langle 0 \quad \text { if } \Phi<0 \\
>0 \text { if } \Phi=0
\end{gathered}
$$

where $\varepsilon_{\mathrm{p}}$ is the plastic strain and $\eta$ the plastic multiplier. The equation for the hardening parameter $\bar{\sigma}$ is given by : $\bar{\sigma}=\sigma(\epsilon)$

Initially a volume fraction of inclusion $\mathrm{f}_{0}$ in the material is considered. These inclusions are considered as voids. During the ductile fracture process, the size of voids increases and coalescence appears for the strain $\varepsilon_{\mathrm{N}}$ with a 
volume fraction $\mathrm{f}_{\mathrm{N}}$. These larger pores increase more rapidly and crack initiation occurs for the volume fraction $f_{i}$. Final fracture occurs for the volume fraction $f_{c}$ :

$$
\begin{gathered}
f^{*}=f \text { for } f \leq f_{i} \\
f^{*}=f_{i}+\frac{\overline{f_{c}}-f_{i}}{f_{c}-f_{i}} \cdot\left(f-f_{i}\right)
\end{gathered}
$$

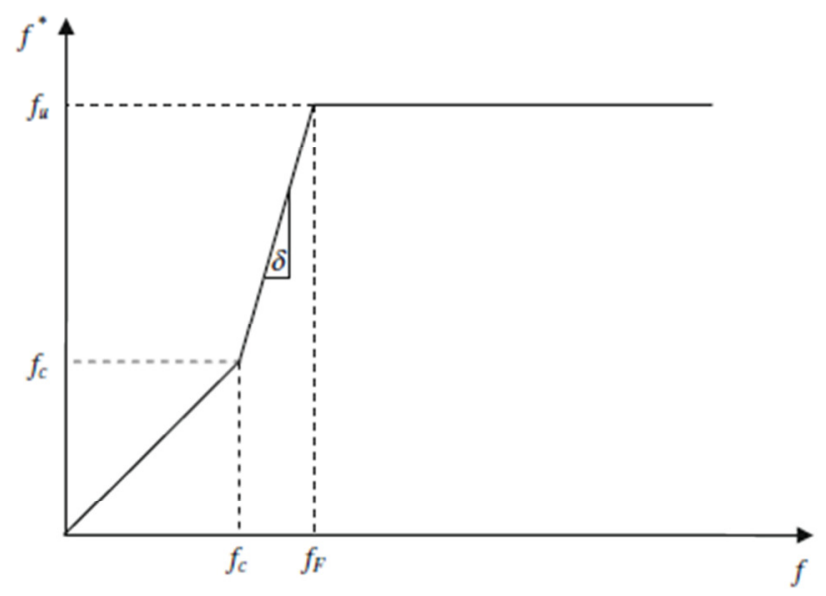

Fig. 2. Evolution of $f$ :

Fig. 4: evolution of effective porosity* with the volume fraction $\mathrm{f}$.

After coalescence, the volume fraction is submitted to a linear acceleration governed by the parameter $\bar{f}_{c}$.

$$
\bar{f}_{c}=\left(q_{3}+\sqrt{q_{1}^{2}-q_{3}}\right) / q_{3}
$$

The evolution equation of the effective porosity or damage in the absence of void nucleation is given by :

$$
\begin{gathered}
\dot{f}=3(1-f) \varepsilon_{p, h} \\
\varepsilon_{p, h} \equiv \frac{1}{3} \operatorname{tr} \varepsilon_{p}
\end{gathered}
$$

The GTN model needs eight constants. Values of these constants for API 5L X65 pipe steel are given in Table 3 and extracted from [10].

Table 3: Values of GTN constants for API 5L X65 pipe steel [33].

\begin{tabular}{|l|l|l|l|l|l|l|l|l|}
\hline $\mathrm{q}_{1}$ & $\mathrm{q}_{2}$ & $\mathrm{q}_{3}$ & $\square_{\mathrm{N}}$ & $\mathrm{f}_{0}$ & $\mathrm{f}_{\mathrm{N}}$ & $\mathrm{f}_{\mathrm{i}}$ & $\mathrm{f}_{\mathrm{c}}$ & $\mathrm{l}_{\mathrm{y}}$ \\
\hline 1.5 & 1.0 & 4.0 & 0.3 & $1.5 .10-4$ & $5.10-4$ & 0.02 & 0.04 & 0.25 \\
\hline
\end{tabular}

The great number of parameters and the difficulty of identifying them are the major handicaps of this method, which requires tensile tests and observation with a scanning electron microscope. In [10], simulation of crack extension using the GTN model is relatively simple, requiring no advanced meshing techniques. The element layer with a width equal to the parameter $1_{\mathrm{y}}$ was defined along the crack propagation path. The initiation and dynamic crack propagation are triggered once the critical crack length $1_{y}$ is reached. The crack propagation distance is limited to five times the outer diameter. The disadvantage of using local damage models for largescale simulations is important. Due to this fine mesh resolution, the number of elements in the pipe model exceeds $10^{6}$, resulting in the enormous CPU time. 


\subsection{Strain rate dependent damage model (SRDD)}

The strain rate dependent damage model (SRDD) is a damage model used for prediction of crack propagation and arrest in gas transmission pipelines [11].

The model consists of three parts: the first part is the elasto-plastic response of an undamaged material, the second part is the damage initiation criterion and the third is the energy for crack extension per unit surface area $R_{f .}$ In the SRDD model, damage initiates when the following condition is fulfilled:

$$
\int \frac{d \varepsilon_{e q}}{\varepsilon_{e q, i}\left(\beta, \varepsilon_{e q}\right)}=1
$$

where $\varepsilon_{e q}$ is the equivalent plastic strain rate, $\varepsilon_{e q}^{\cdot}$ the equivalent plastic strain rate, $\varepsilon_{e q, i}$ the equivalent plastic strain at damage initiation and $\beta$ the stress triaxiality. The resistance to crack extension is given by :

$$
\mathrm{R}_{f}=\int_{u_{e q, i}}^{u_{e q, c}} \sigma d u_{e q}
$$

where $u_{e q}$ is the equivalent plastic strain at fracture, $u_{e q, i}$ is the equivalent plastic displacement at damage initiation and $u_{e q, c}$ is equivalent plastic displacement at fracture. $\mathrm{R}_{\mathrm{f}}$ is considered to be a material property.

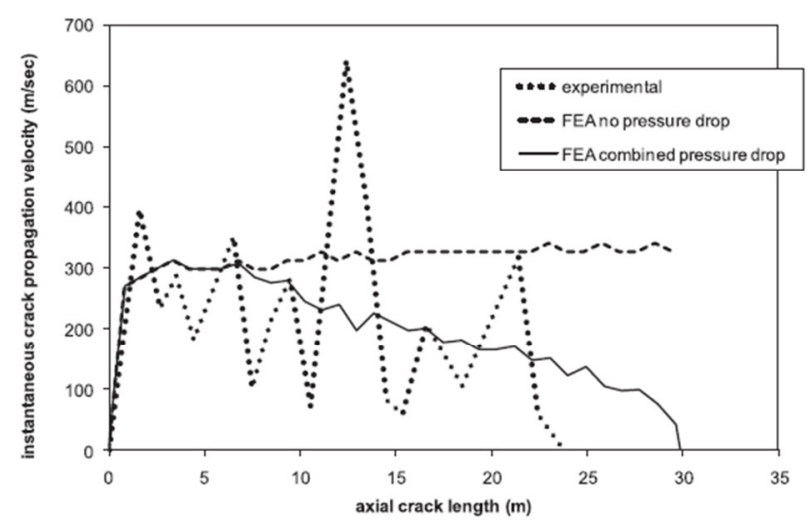

Fig 5 : Simulation of crack velocity with crack length with and without combined pressure drop using the SRDD model [11].

To avoid mesh dependence, a characteristic length parameter is introduced and stress-displacement relationship is used instead of the stress-strain. The element is considered failed when its plastic work exceeds the $R_{f}$ multiplied by the element area.

\section{CTOA MODEL}

Crack extension is modelled by the finite element method using the CTOA criterion coupled with the node release technique. The node release technique algorithm has been presented in an earlier study [8]. It is based on the assumption that cracks grow step-by-step and each step has the length of one mesh element. Triggering of crack extension at each step is given by a CTOA-based criterion.

Boundary conditions were imposed on the pipe, in order to make the simulation as real as possible. They consisted of imposing symmetry along the crack plane and constraining the closed part of the crack with fixed nodes in the circumferential direction. These fixed nodes were then removed by the nodal release user subroutine to provoke crack extension.

Acting tractions on uncoupling nodes at the crack faces are reduced as the crack opens. This event occurs when CTOA reaches its critical value and then the representative node of the crack tip is released and the new position of the crack is deduced. This algorithm requires several time increments and a fine mesh (i.e. element size under $1.5 \mathrm{~mm}$ ) around the crack tip for accurate evaluation of the CTOA. In this approach, the evolution of the crack strictly depends on the mesh element size around the crack tip, since it governs the amount of the crack advance. 
Moreover, the advancing process is not really continuous since a proper iteration scheme is necessary to evaluate the dynamic crack growth accurately during the integration time.

Table 4 gives a summary of different methods of modelling crack extension showing the number of parameters, advantages, and disadvantages. CTOA is an eligible one-parameter fracture resistance for ductile crack extension.

Table 4: Different methods of modelling crack extension

\begin{tabular}{|c|c|c|c|c|}
\hline & $\overline{\mathrm{CZM}}$ & Gurson & SRDD & CTOAc \\
\hline $\begin{array}{l}\text { Number of } \\
\text { parameters }\end{array}$ & 2 & 8 & 3 & 1 \\
\hline $\begin{array}{c}\text { Advantage } \\
\mathrm{s}\end{array}$ & $\begin{array}{l}\text { Simple model; } \\
\text { Ability to } \\
\text { model } \\
\text { branching } \\
\text { crack }\end{array}$ & $\begin{array}{l}\text { Linked to the micro- } \\
\text { mechanisms; } \\
\text { Constraint effect taken } \\
\text { into account }\end{array}$ & $\begin{array}{l}\text { Directly linked } \\
\text { to resistance to } \\
\text { crack extension }\end{array}$ & $\begin{array}{l}\text { Directly } \\
\text { linked to } \\
\text { crack } \\
\text { extension }\end{array}$ \\
\hline $\begin{array}{l}\text { Disadvanta } \\
\text { ges }\end{array}$ & $\begin{array}{l}\text { Needs } \\
\text { predefined } \\
\text { crack path }\end{array}$ & $\begin{array}{c}\text { Non-standard } \\
\text { calibration; } \\
\text { Mesh-dependence; } \\
\text { Long computational } \\
\text { time }\end{array}$ & $\begin{array}{l}\text { Resistance to } \\
\text { crack extension } \\
\text { sensitive to } \\
\text { gauge length }\end{array}$ & $\begin{array}{c}\text { Large } \\
\text { scatter of } \\
\text { CTOA } \\
\text { values }\end{array}$ \\
\hline
\end{tabular}

\section{NUMERICAL SIMULATION OF CRACK PROPAGATION AND ARREST BASED ON CTOA}

Conditions for crack propagation or arrest are given by a coupled fluid-structure problem.. Crack propagation speed is controlled by pressure distribution on the opening pipe. If the decompression wave is faster than the propagating crack fracture, the pressure at crack tip will decrease, and the crack will arrest.

In terms of a limit state design, the arrest pressure can be predicted by solving the Equation (13) between the fracture resistance and component stress, which depend on the pipeline dimensions, internal pressure and material strength. This material resistance is balanced with a component stressing that is determined involving specific pipe dimensions, decompression pressure $\mathrm{p}_{\mathrm{d}}$ and material strength. The arrest pressure can be predicted by solving the equation between the stress state at crack tip :

$$
\left.2_{i j}\left(p_{d}\right)\right\rangle=\left[\sigma_{i j, c}\left(p_{a r}\right)\right\rangle
$$

In principle, to solve the gas depressurisation problem, one has to solve a coupled gas-solid thermomechanical problem. There are specialised codes developed for this purpose, e.g. GASDECOM [13].

Generally simplified gas depressurisation models have been proposed in literature, which only predict gas pressure as a function of time and distance from the crack tip. These models are based on the isentropic expansion of ideal gas, where a pipe is considered a large pressure vessel with constant volume. These assumptions are justified by the fact that crack propagation cannot outrun the decompression wave. This means that the crack tip is always present in pipe section affected by the decompression process. Gas pressure ahead of the crack depends only on time. This simplification is justified by the fact that the crack propagation speed is at most 200-300 m/s, which is lower than the wave speed in the pressurized gas, estimated at about $400 \mathrm{~m} / \mathrm{s}$ [14]. This means that the crack cannot outrun the pressure drop wave, and the crack tip will always be in a segment of the pipe with falling pressure. The drop pressure ahead of the running crack tip is given as:

$$
p_{d}(t)=p_{0} \cdot \exp (k t)
$$

$\mathrm{k}$ is a constant expressed as: 


$$
k=-\frac{A}{V_{0}} \sqrt{\frac{R T}{W_{g}}}
$$

where $\mathrm{A}$ is the cross-sectional area of the pipe, $\mathrm{V}_{0}$ is the initial volume, $\mathrm{R}$ is the universal gas constant, $\mathrm{T}$ is the average temperature of the gas and $\mathrm{W}_{\mathrm{g}}$ is the molecular weight of the gas,

$\mathrm{k}=-7.5$ [13]. Instantaneous internal pipe pressure was imposed along a certain distance behind the crack-tip node: Fig. 6. This distance was given by the cohesive zone model of Dugdale-Barenblatt [15]. The distance is $2 b=3 \sqrt{R . t}$, where $\mathrm{R}$ and $\mathrm{t}$ are outer radius and wall thickness, respectively.

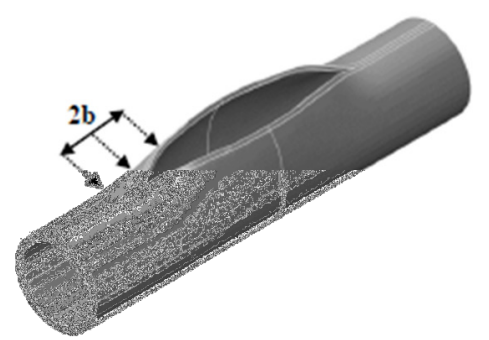

Fig. 6 : Zone length where gas pressure is imposed on coupled nodes.

Pressure drop behind the crack tip is expressed only as a function of distance. For distances exceeding 1.75 pipe diameters behind the crack tip, the pressure is considered zero. It is also possible to assume a linear pressure drop behind the running crack tip [11]:

$$
p_{b}(z)=p_{0}\left(1-\frac{z}{1.75 D}\right)
$$

where $\mathrm{p}_{\mathrm{b}}(\mathrm{z}, \mathrm{t})$ is the gas pressure behind the crack tip, which is a function of the distance $\mathrm{z}$, and of time $t$ and $\mathrm{p}_{0}$ is the initial gas pressure prior to the appearance of the through thickness crack.

The use of CTOA to model the ductile crack propagation of thin structures has been validated by several authors $[16,17]$. To simulate crack propagation, the CTOA fracture criterion is introduced in a numerical model using the node release technique. Condition of node release is given by the following equation:

$$
\mathrm{CTOA}\left(\mathrm{p}_{\mathrm{ar}}\right)=\mathrm{CTOA}_{\mathrm{c}}
$$

where CTOA is the crack tip opening angle induced by the current pressure, $\mathrm{p}_{\mathrm{ar}}$ the arrest pressure and $\mathrm{CTOA}_{\mathrm{c}}$ the fracture resistance.

The node release technique is based on the assumption that the crack growth is described by uncoupling nodes at the crack faces, whose acting tractions are reduced as far as the crack opens. When the CTOA reaches its critical value $\left(\Psi=\Psi_{\mathrm{c}}\right)$, the representative node of the crack tip is released and a new position of the crack is deduced. Each propagation step corresponds to the size of a mesh element (see Fig. 7). In this method, crack evolution depends on the size of mesh elements around the crack tip, since it governs the amount of the crack advance. Moreover, the advancing process is not really continuous, since a proper iteration scheme is necessary to evaluate the dynamic crack growth during the integration time accurately. The method requires an a priori knowledge of the crack propagation path. The simulation is performed on a pipe with an outer diameter of $355 \mathrm{~mm}$, wall thickness of $19 \mathrm{~mm}$, and length of $6 \mathrm{~m}$. The studied pipe is made of API 5L X65 steel with a critical CTOA value of $20^{\circ}$.

The computing phase begins by generating a 3D finite element implicit dynamic analysis. Because of the symmetry of the crack planes, only a quarter of the pipeline was analysed. A combined 3D-shell mesh was used to reduce the computing time. A total of 50976 eight-node hexahedral elements were generated along the crack path and combined with 6000 shell elements. 


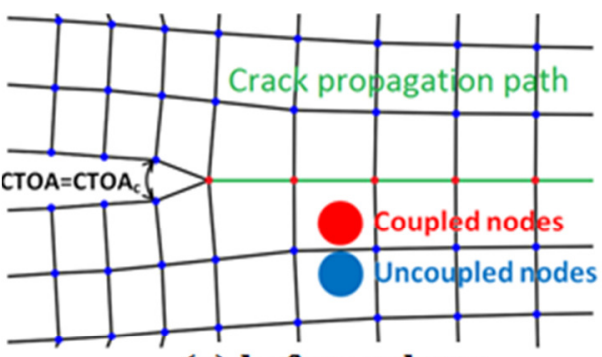

(a) before release

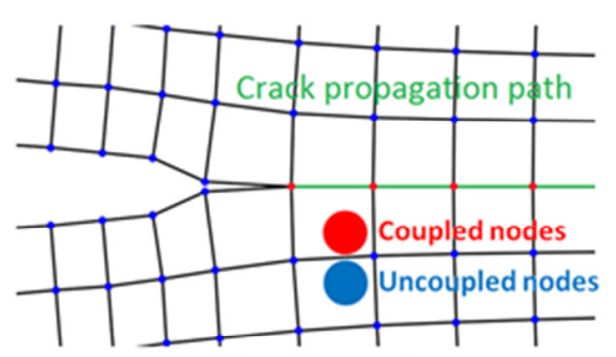

(b) after release

Fig. 7: Crack propagation according to the node release technique and the CTOA criterion, mode I and 2D.

Crack arrest in gas pipelines was performed with the release user subroutine, in conjunction with the FEM ABAQUS code. The computing phase begins by generating a $3 \mathrm{D}$ finite element implicit dynamic analysis. Because of the symmetry of the crack planes, only a quarter of the pipeline was analysed.

Crack extension from an initial crack-like defect is computed using the described model. Running crack propagation along the tube consists of two stages: a boost phase, where the crack reaches its full velocity in a few milliseconds, followed by a steady stage at constant speed. The absence of a deceleration phase is explained by the absence of a pressure drop.

The crack velocity increases with the initial pressure. Ten simulations were performed at different levels of pressure in the range of $28-60 \mathrm{MPa}$.

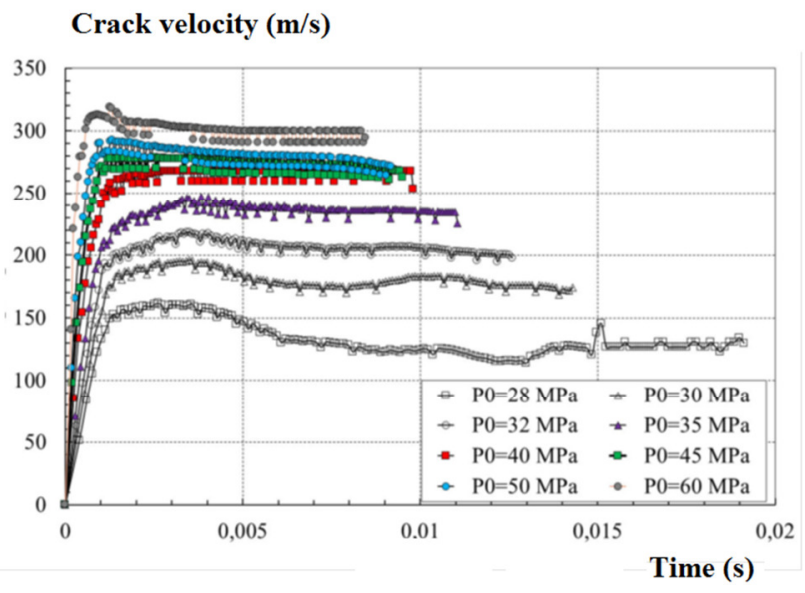

Fig. 8 : Crack velocity pipe versus time for different initial pressure in API 5L X65, diameter 355 mm and thickness $19 \mathrm{~mm}$.

The results indicate that the stationary crack velocity $\mathrm{V}_{\mathrm{c}}[\mathrm{m} / \mathrm{s}]$ increases with initial pressure $\mathrm{p}_{0}[\mathrm{MPa}]$ according to:

$$
V_{c}=284.2 *\left(\frac{p_{d}}{25.8}-1\right)^{0.193}
$$

$\mathrm{p}_{0}$ has been replaced by decompression pressure because if $\mathrm{V}_{\mathrm{c}}>\mathrm{V}_{\mathrm{d}} \mathrm{p}_{0}=\mathrm{p}_{\mathrm{d}}$

Qualitatively, this equation is consistent with the experimental results reported by Battelle, HLP, and many other authors [2-4]. Crack extension at arrest is obtained from the graph of crack velocity versus half the crack extension, to take into account the symmetry of the problem. For the aforementioned conditions of 
geometry, material, and initial pressure, the numerical simulation gives a crack extension of $42 \mathrm{~m}$, which is of the same order of magnitude as those obtained experimentally.

\section{INFLUENCE OF GEOMETRICAL AND MATERIAL PARAMETERS ON CRACK ARREST AND VELOCITY}

Prediction of crack arrest and crack velocity after fracture initiation in a pipe submitted to internal pressure is modelled here using critical CTOA as a parameter representative of the fracture resistance to crack extension $\mathrm{R}_{\mathrm{f}}$. This parameter is sensitive to geometry in general and to diameter and thickness for pipe particularly. It is also sensitive to material through its flow stress $\sigma_{0}$.

The influence of these different parameters on CTOA has been described by [14] and is given by the general form:

$$
\text { CTOA }=C\left(\frac{\sigma_{h}}{E}\right)^{m}\left(\frac{\sigma_{h}}{\sigma_{0}}\right)^{n}\left(\frac{D}{t}\right)^{q}
$$

where $\mathrm{m}, \mathrm{n}$, and $\mathrm{q}$ are dimensionless constants and $\mathrm{C}$ is expressed in degrees; $\sigma_{\mathrm{h}}$ is the hoop stress $(\mathrm{MPa}), \sigma_{0}$ is the flow stress (MPa), D is the diameter $(\mathrm{mm})$, and $\mathrm{t}$ is thickness $(\mathrm{mm})$. The following values can be used for methane: $\mathrm{C}=106, \mathrm{~m}=0.753, \mathrm{n}=0$. and $\mathrm{q}=0.65$. Influence of the quantities $\sqrt{D t}$ on initial pressure $\mathrm{p}_{0}$ is introduced by through the Folias factor [2] :

$$
p_{0}=\sigma_{h} \frac{2 t}{D}=\frac{\sigma_{0}}{M_{F}} \cdot \frac{2 t}{D}
$$

where $\mathrm{M}_{\mathrm{F}}$ is the Folias correction factor :

$$
M_{F}=\left[1+1.255 \cdot\left(\frac{a}{\sqrt{D t / 2}}\right)^{2}-0.0135 \cdot\left(\frac{a}{\sqrt{D t / 2}}\right)^{4}\right]^{1 / 2}
$$

\subsection{Influence of thickness}

Arrest pressure and crack velocity have been computed using the aforementioned node release technique with four different pipe wall thicknesses [5, 10, 15, $19.05 \mathrm{~mm}$ ]. In each case, the pipe has a diameter of $355 \mathrm{~mm}$ and is made of steel API 5L X65 with a yield stress equal to $465 \mathrm{MPa}$. Results are reported in Figs. 9 and 10.

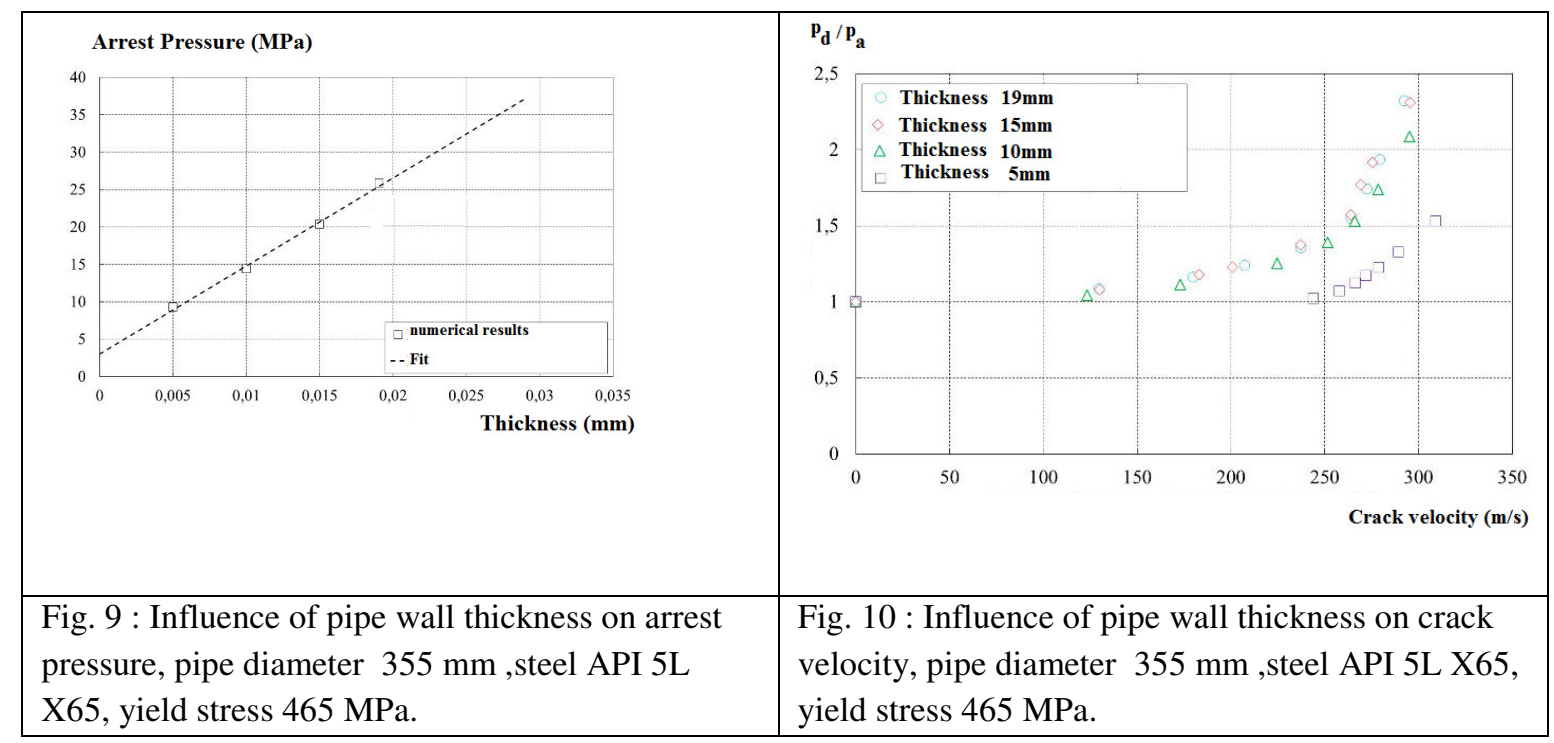


Fig. 10 shows a linear evolution between arrest pressure and wall thickness. On Fig. 11, the ratio of decompression wave and arrest pressure is plotted versus the crack velocity for the four studied wall thicknesses. The velocity obeys the general law:

$$
V_{c}=H \cdot\left(\frac{p_{d}}{p_{a}}-1\right)^{\beta}
$$

where $\mathrm{H}$ is a material constant that depends on initial pressure, flow stress and resistance to crack extension of the material, $\beta$ another constant. There is no influence of wall thickness for values above $10 \mathrm{~mm}$. Higher velocities for low values of the wall thickness may be the result of a mesh problem without certainty. However a wall thickness of $5 \mathrm{~mm}$ for a pipe of $355 \mathrm{~mm}$ of diameter is not realistic and generally wall thickness for a gas pipe is over $8 \mathrm{~mm}$.

Five simulations to study the influence of the diameter on crack velocity and arrest pressure have been performed. The pipe thickness has been chosen as $19.05 \mathrm{~mm}$ and pipe diameter as $0.304,0.355,0.393,0.61$ and $0.91 \mathrm{~m}$. The evolutions of arrest pressure and crack velocity pressure have been plotted versus the pipe diameter: Figs. 11 and 12. We notice that the arrest pressure is a decreasing function of the diameter of the pipeline. We also highlight a minor effect of the pipe diameter on crack velocity.

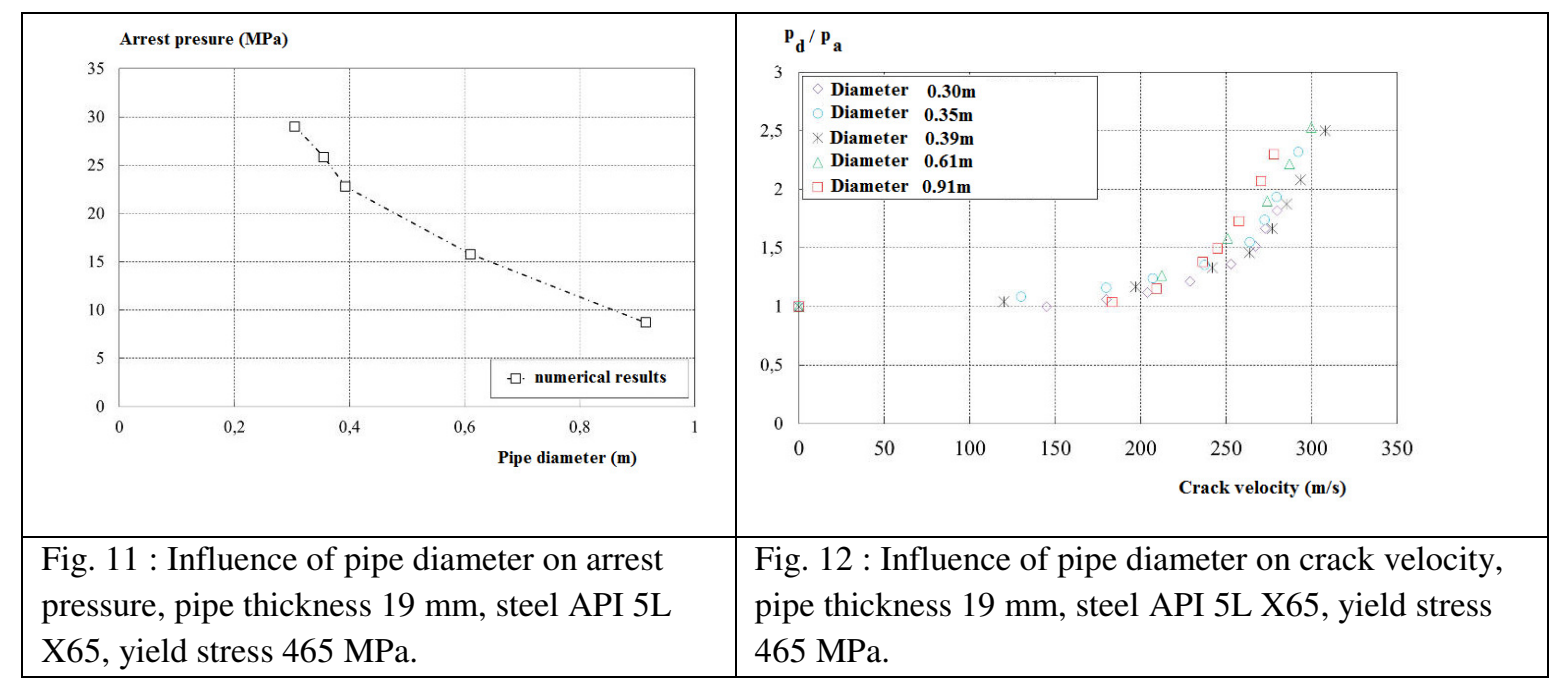

\begin{tabular}{|l|l|l|l|l|l|l|}
\hline & \\
\hline
\end{tabular}

\subsection{Influence of flow stress}

We performed several simulations of pipe bursting and modified the yield stress in the interval 320-735 MPa keeping the other parameters identical, i.e., the geometry of the pipe, the strain hardening and the mesh size. A linear function between the arrest pressure and the yield stress is observed: Fig. 13. In Fig. 14, we notice an 
increase of the crack velocity with increasing yield strength. These results are consistent with the fact that the increases of the yield stress result in a decrease in toughness and therefore the resistance to crack extension.

6.3Influence of CTOA Influence of the resistance to crack extension has been studied, over 40 simulations keeping all the parameters of the numerical model identical. Only the value of $\mathrm{CTOA}_{\mathrm{c}}$ was modified in the range $5-20^{\circ}$. Simulations of static and dynamic type provide the evolution of the arrest pressure and crack velocity versus the resistance to crack extension, expressed in terms of $\mathrm{CTOA}_{\mathrm{c}}$ : Figs. 15 and 16.

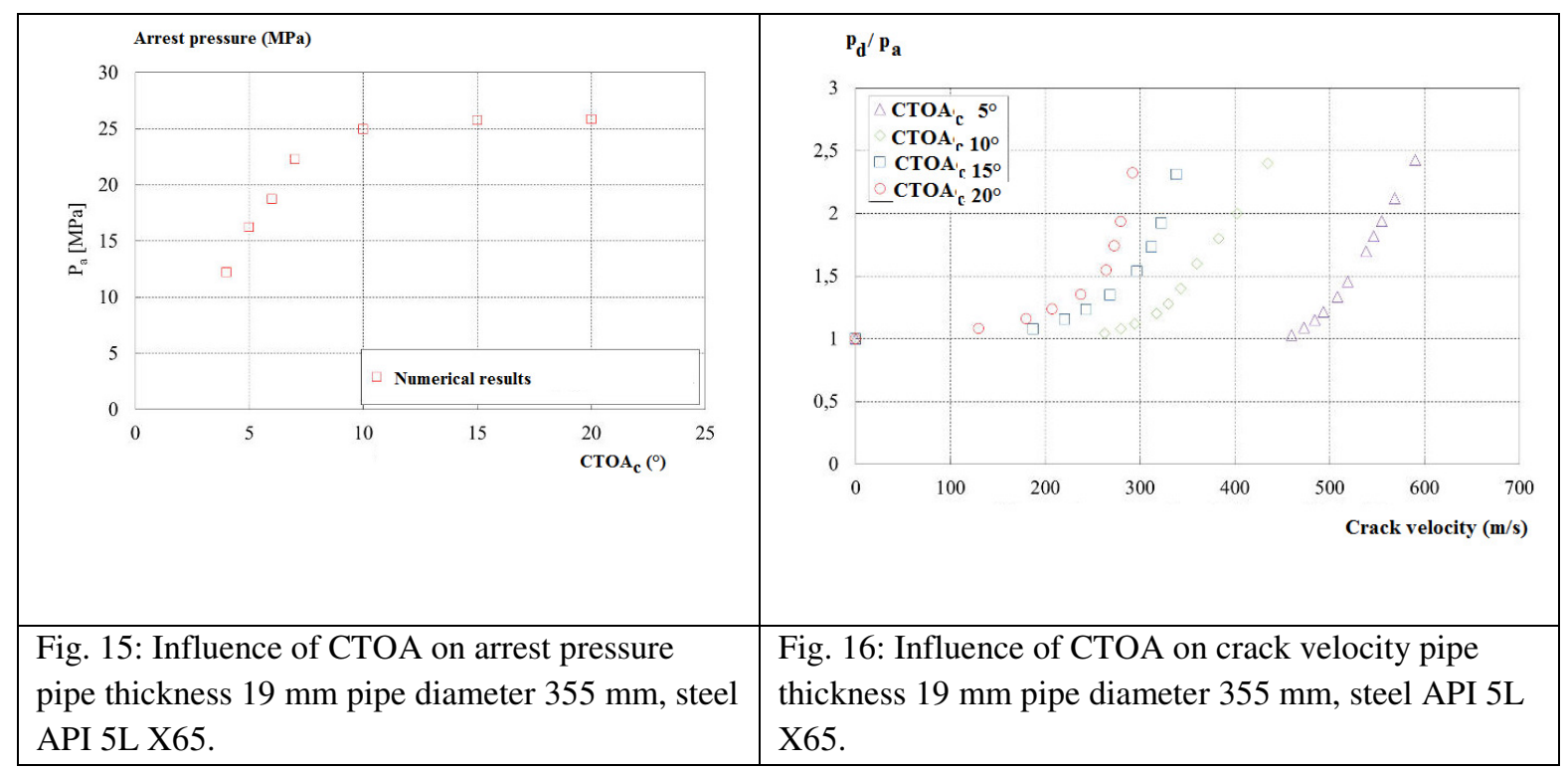

The arrest pressure increases relatively linearly versus resistance to crack extension until a value of $\mathrm{CTOA}_{c}$ equal to $10^{\circ}$. After asymptotically, the arrest pressure stabilises to a value of arrest pressure that depends on initial pressure, geometry of the pipe and material flow stress.

For the same decompression wave pressure, the crack propagation velocity is inversely proportional to the resistance to crack extension of the material, which is the dominant parameter.

\section{TWO CURVES METHOD BASED ON CTOA}

During the crack-propagation process, the gas escapes through the opening created in the wall of the pipe by the crack. Indeed, a decompression wave begins to propagate through the pipe at a speed of the order of 300-400 $\mathrm{m} / \mathrm{s}$. A number of models have been developed for predicting the gas decompression wave speed. Many of these assume a one-dimensional (along the pipe axis) and isentropic flow and use the Finite Difference Method (FDM) or the Method of Characteristics (MOC).

BTCM is a model that assumes a one-dimensional, frictionless, isentropic, and homogeneous fluid and uses the Benedict-Webb-Rubin-Starling equation of state with modified constants to estimate the thermodynamic parameters during the isentropic decompression.

According to this one-dimensional flow model analysis and experimental results obtained from shock tube tests, the decompression pressure at the crack tip $\mathrm{p}_{\mathrm{d}}$ is given by equ.1:

It was proven by Battelle [2] that the ratio between the gas decompression wave and crack-propagation speed has a major role in the dynamics of crack growth. Indeed, if the crack propagates faster than the decompression wave, the crack tip is always loaded by the initial pressure $p_{0}$. Otherwise, the crack tip is progressively less and less loaded, up to crack arrest.

\subsection{Crack velocity versus decompression pressure}

The crack velocity versus decompression is expressed by the general following equation, which can be found in different TCMs as BTCM [2] HLP [3] and HLP-Sumitomo [4] methods: 


$$
V_{c}=\alpha \cdot \frac{\sigma_{0}}{\sqrt{R_{f}}} \cdot\left(\frac{p_{d}}{p_{a}}-1\right)^{\beta}
$$

where $\alpha, \beta$ parameters are pipe geometry dependants. $\sigma_{\mathrm{o}}$ is the flow stress and $\mathrm{R}_{\mathrm{f}}$ is the resistance to crack extension expressed in terms of CTOA.

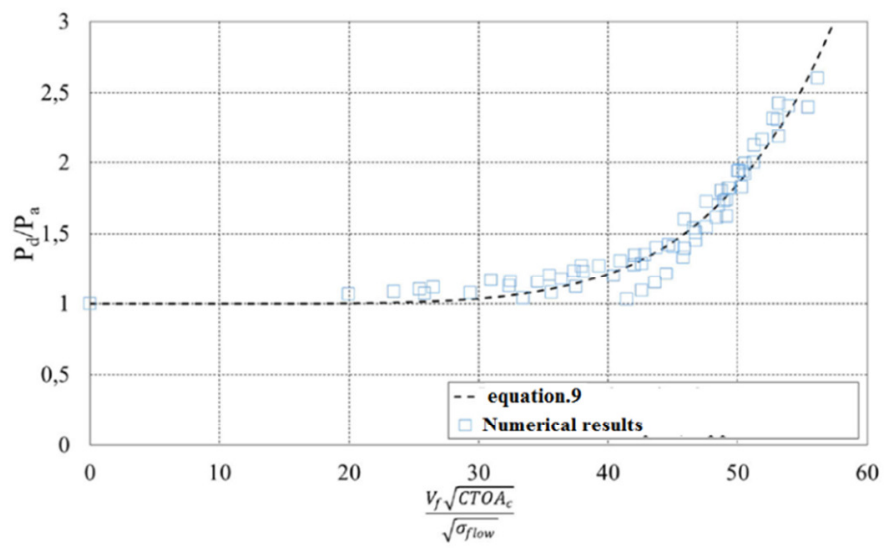

Fig. 17 : evolution of the ratio $p_{d} / p_{a}$ versus the parameter $\left(V_{c} \sqrt{C T O A}+\sqrt{\sigma_{0}}\right)$.

Crack velocity and arrest pressure were computed for a pipe made in steel API 5L X65 with a diameter of $355 \mathrm{~mm}$ and a thickness of $19 \mathrm{~mm}$. Initial pressure, po varies from 28-60 MPa. Results are reported in a graph of $p_{d} / p_{a}=f\left(V_{c} \sqrt{C T O A}{ }_{c} / \sigma_{0}\right)$ similar to the original HLP formula and in a graph $p_{d} / p_{a}=$ $f\left(V_{c} \sqrt{C T O A}_{c} / \sqrt{\sigma_{0}}\right)$ : see Fig. 17. It appears that the second approach leads to a better correlation coefficient and data are fitted by Equation (25).

$$
V_{c}=6.78 \frac{\sqrt{\sigma_{0}}}{\sqrt{\text { CTOA }_{c}}}\left(\frac{p_{d}}{p_{a}}-1\right)^{0.162}
$$

The square root of the flow stress instead the flow stress itself operates in this equation.

\subsection{Arrest pressure equation}

The arrest pressure is expressed by the following general equation, according to the BTCM [2], HLP [3] and HLP-Sumitomo [4] methods.

$$
p_{a}=A \cdot \frac{t}{D} \cdot \sigma_{0} \cdot \cos ^{-1} \exp \left(\frac{-. \pi E \cdot R_{f}}{24 \sigma_{0}^{2} \sqrt{D t / 2}}\right)
$$

A is a parameter that depends of the ratio diameter-thickness $D / t$. The arrest pressure is a linear function of the flow stress, which is confirmed by the numerical results. In the BTCM, the flow stress is defined as :

$$
\sigma_{0}=\sigma_{y}+69 \mathrm{MPa}
$$




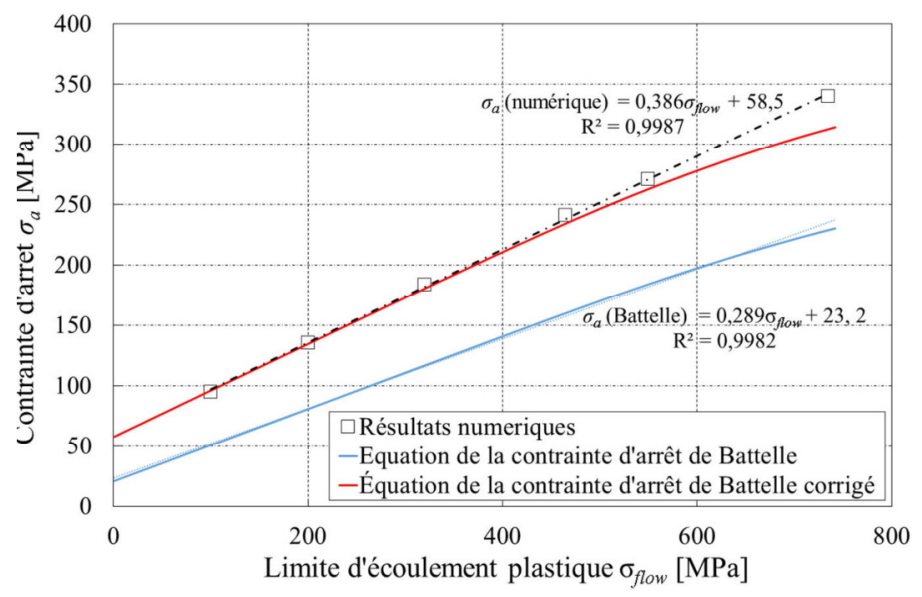

Fig. 18. Numerical simulation of arrest pressure versus flow stress using CTOA as resistance to crack extension. Pipe made in API 5L X65 steel, pipe diameter $355 \mathrm{~mm}$, thickness $19 \mathrm{~mm}$.

To take into account the strain hardening, the following definition is used :

$$
\sigma_{0}=\left(\sigma_{y}+\sigma_{u}\right) / 2
$$

The arrest stress is defined as :

$$
\sigma_{a}=\frac{p_{a} D}{2 t}
$$

In Fig. 18, the arrest stress has been plotted versus yield stress. Numerical simulations confirm the linear dependence of the arrest stress with the flow stress.

Several burst tests carried out at Batelle have been reported by Kiefner et al [18]. They concern ductile fracture initiation, propagation and arrest in cylindrical vessels that range from 168-1219 $\mathrm{mm}$ and made in steel with yield stress in the range 151- $765 \mathrm{MPa}$. For these tests, the ratio of arrest stress and flow stress is plotted versus the parameter $\frac{\pi E \cdot C T O A_{C}}{24 \sigma_{0}^{2} \sqrt{D t / 2}}$.

The arrest pressure curve separates the arrest zone with data as a triangle to crack extension zone with data as square. The flow stress according to Equation (28) is equal to $511 \mathrm{MPa}$ and the ratio $\mathrm{D} / \mathrm{t}=18.7$. The best fit confirms the $\left(\cos ^{-1} \exp \right)$ dependence of the arrest pressure with the parameter $\frac{\pi E . C T O A_{c}}{24 \sigma_{0}^{2} \sqrt{D t / 2}}$ with the following equation, similar to the BTCM's equation (Fig. 19):

$p_{a}=B \cdot \frac{t}{D} \cdot \sigma_{0} \cdot \cos ^{-1} \exp \left(\frac{-. \pi E \cdot C T O A_{c}}{24 \sigma_{0}^{2} \sqrt{D t / 2}}\right)$

with $\mathrm{B}$ as another constant.

\section{CONCLUSIONS}

Fracture resistance to crack extension $R_{f}$ refers strictly to crack propagation. Therefore the use of fracture tests including energy for fracture initiation (Charpy or DWTT tests) is doubtful. A parameter defined from the R curve like CTOA is therefore preferable. Numerical simulation of crack extension in pipes can be made using the cohesive zone model, a critical damage with the Gurson-Tvergaard-Needleman model, critical damage given by SRDD model or a critical crack opening angle. The use of CTOA to model the ductile crack propagation of thin structures is justified by the fact that it is a one-parameter criterion and results are not very sensitive to pipe geometry. To simulate crack propagation, the CTOA fracture criterion is introduced in a numerical model using the node release technique. Results of numerical modelling indicate that there is no influence of wall thickness 
for values above $10 \mathrm{~mm}$ and a minor effect of the pipe diameter on crack velocity. Crack velocity increases with increasing yield strength, and the arrest pressure stabilises to a value that depends on initial pressure, geometry of the pipe, and material flow stress.

For the same decompression wave pressure, the crack propagation velocity is inversely proportional to the resistance to crack extension of the material, which is the dominant parameter. The crack velocity versus decompression is expressed by a $\mathrm{CTOA}_{\mathrm{c}}$ function versus the parameter $\frac{\pi E . C T O A_{c}}{24 \sigma_{0}^{2} \sqrt{D t / 2}}$.

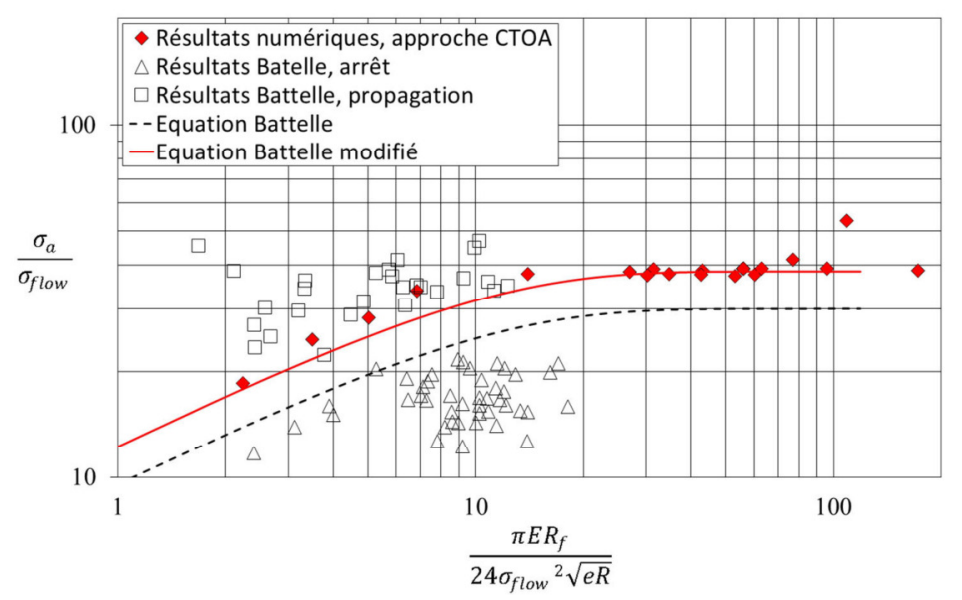

Fig. 19 : dependence of the arrest pressure with the parameter $\frac{\pi E \cdot C T O A_{C}}{24 \sigma_{0}^{2} \sqrt{D t / 2}}$.

\section{REFERENCES}

[1] R. J. Eiber. “Fracture Propagation ”. Paper I. Proc. 4th Symp.on Line Pipe Research. AGA catalogue no. L30075,(1969).

[2] W.A. Maxey. 5th Symp. Line Pipe Research, PRCI Catalog No. L30174, Paper J,(1974)

[3] E.Sugie, M.Matsuoka , H.Akiyama, T.Mimura , Y.Kawaguchi. “ A study of shear crack-propagation in gaspressurized pipelines", J. Press. Vessels Technol., 104, (4):338-343, (1982).

[4] R.Higuchi, H.Makino, I.Takeuchi. "New concept and test method on running ductile fracture arrest for high pressure gas pipeline”. In: 24th World Gas Conf., WGC 2009, Vol. 4, International Gas Union, Buenos Aires, Argentina, 2730-2737. (2009)

[5] S. Chapuliotb, S. Marieb, I. Kayserb. “ Derivation of J-resistance curve for through wall cracked pipes from crack mouth opening displacement”. International Journal of Pressure Vessels and Piping, 83 : 686-699, (2006).

[6] G. Demofonti, G.Buzzichelli, S.Venzi, M. Kanninen. “Step by step procedure for the two specimen CTOA test”. In: Denys R (ed.) Proc. 2nd Int. Pipeline Technology Conf., Pipeline Technology, vol. II, 11-14

September, Ostend, Belgium, Elsevier Science : 503-512, (1995).

[7] H.Andersson “A finite element representation of stable crack growth". J. Mech. Phys. Solids, 21: 337-356, (1973).

[8] M.Benamara, G.Pluvinage, J.Capelle, Z.Azari. "Prediction of arrest pressure in pipe based on CTOA".

Journal of pipe and engineering, (2015).

[9] Cheng Cen. "Characterization and Calculation of Fracture Toughness for High Grade

Pipes". PhD thesis, University of Alberta, (2013).

[10] I. Scheider, A. Nonn, A.Völling, A.Mondry, C.Kalwa. “A damage mechanics based evaluation of dynamic fracture resistance in gas pipelines". Procedia Mater. Sci., 3, 1956-1964, (2014).

[11] F. Oikonomidis, A. Shterenlikht, C.E. Truman "Prediction of crack propagation and arrest in X100 natural gas transmission pipelines with a strain rate dependent damage model (SRDD). Part 2: Large scale pipe models with gas depressurisation » International Journal of Pressure Vessels and Piping, 122 : 15-21,(2014).

[12] B.Cotterell, J. K. Reddel, , “The essential work of plane stress fracture”, Int. J. of Fracture, No. 13, pp. 267-277, (1977).

[13] R. Eiber, T. Bubenik, and W. Maxey, " GASDECOM, computer code for the calculation of gas decompression speed that is included in fracture control technology for natural gas pipelines. NG-18 Report 208," American Gas Association Catalog,(1993). 
[14] G.Demofonti, G.Mannucci , H.G. Hillenbrand, D.Harris.” Evaluation of X100 steel pipes for high pressure gas transportation pipelines by full scale tests". Int. Pipeline Conf., Calgary, Canada, (2004).

[15] W.Maxey, "Dynamic crack propagation in line pipe", In: Analytical and Experimental, Fracture Mechanics, ed. Sih G.C and Mirabile M: 109-123, (1981).

[16] A. S. Gullerud, R. H. Dodds, R. W. Hampton, et D. S. Dawicke, « Three-dimensional modeling of ductile crack growth in thin sheet metals: computational aspects and validation », Engineering Fracture Mechanics, vol. 63, n. 4: 347-374, (1999).

[17] R.W. Hampton and D. Nelson, « Stable crack growth and instability prediction in thin plates and cylinders », Engineering Fracture Mechanics, vol. 70, no. 3-4: 469-491, febr. (2003).

[18]J.F. Kiefner, R.J Eiber, and A.R. Duffy. "Ductile fracture initiation, propagation and arrest in cylindrical vessels". ASTM STP, 514 :70-81, (1972). 